\title{
Gunshot injuries: patterns, presentations, and outcomes of civilian hospital experiences in a developing country setting
}

MOHAMED Daffalla Awadalla GISMALLA ( $\square$ mohadaff22@gmail.com )

University of Gezira Faculty of Medicine

Mohammed Bakhiet

University of Kordofan Faculty of Medicine and Health Sciences

Mohammedbabalrahma Koko

University of Kordofan Faculty of Medicine and Health Sciences

Abdelrahim Kabbashi

University of Kordofan Faculty of Medicine and Health Sciences

Research article

Keywords: Epidemiology, Gunshot injuries, Gunshot wound, Sub-Saharan Countries, Sudan

Posted Date: July 15th, 2020

DOl: https://doi.org/10.21203/rs.3.rs-42232/v1

License: (c) (i) This work is licensed under a Creative Commons Attribution 4.0 International License.

Read Full License 


\section{Abstract}

\section{Background}

Gunshot injuries are considered a burden as well as one of the intricate emergencies in civilian medical practice. In this study we aim to determine the pattern of presentation and management outcome in a general hospital in a sub-Saharan country.

\section{Methods}

This is a retrospective, hospital-based study conducted between January 2015- December 2019 in a general teaching hospital, to review the clinical presentation and management outcome of gunshot injuries. All patients' records were reviewed during the study period.

\section{Results}

One hundred fifty-seven patients were included in the study, with male predominant $83 \% .40 \%$ are between 19-30 years of age, with patients under 18 years of age comprising $17 \%$ of the population.

The anatomical sites most commonly affected by gunshot were the lower limb (41.4\%) and upper limb $(22.9 \%)$, and the least impacted site is the perineum (1.9\%). The most common diagnoses among the patients in this study were limb fractures (49.7\%) and soft tissue injuries (28.7\%). Specific treatment in this study is wound debridement, which was done for 91 (58.0 \%) patients. Bone fixation, laparotomy and chest tube insertion were done for the rest of the patients. More than $120(75 \%)$ of patients were treated and discharge in a good condition and $27(17.2 \%)$. The mortality rate in this study group was $15.3 \%$.

\section{Conclusion}

Most of the patient in this study were young males. Upper and lower limb fractures are the most common presentations. Wound debridement, bone fixation and laparotomy are the most common treatments with significant success rates, despite prolonged hospital stay.

\section{Background}

Accidents and injuries primarily affect young people and often lead to either premature death or disabilities. They are estimated to be responsible for $1 / 4$ of disabilities in some countries [1]. Each year, different types of Injuries lead to 5.1 million deaths which represent about $10 \%$ of the global mortality and are predicted to cause 7.4 million deaths annually by $2030[2,3]$.

Gunshot injuries are considered to be a global public health concern [4]. It is now more common than the past and contribute to significant increases in morbidity and mortality. Prevalent causes of gunshot injuries in Africa include communal clashes, military violence, armed robberies and political conflicts [5].Gunshot injuries can be classified anatomically according to the site of body affected. Such common 
sites include the head, neck, pelvis, limbs or multiple regions combined, which has high morbidity and mortality rates.

In USA approximately 30,000 patients are hospitalized for gunshot injuries yearly, and 2500 of them die in the hospital. Firearm homicides are 19 times more prevalent in the USA than other higher income countries [6]. In Africa, firearm injuries represent a major health problem. South Africa is an example of a country that faces this problem, which creates a huge burden on the healthcare resources [7]. Firearm injuries were estimated to amount to almost 55,000 in 2012 in South Africa [8].

In Sudan the incidence of injuries for different cause was 82.0/1000 person per year, with low socioeconomic status population placed at an increased risk. There is a lack of reliable resources documenting injury-related deaths [2]. Regarding gunshot injuries in Sudan, there is no study which we know that has documents and report the incidence, causes or the outcome. So, we look for Evidencebased data to plan and promote management and prevention protocol. This study was conducted to investigate the pattern of gunshot injuries and its impact on case management, along with patient morbidity and mortality.

\section{Methods}

\section{Study design}

This is retrospective, hospital-based study was conducted between January 2015 and December 2019 in Elobeid teaching hospital, to review the clinical presentation and case management outcomes of gunshot injuries. All the patients' records were reviewed during the study period.

\section{Setting}

Emergency and trauma patients were referred to Elobeid Teaching hospital emergency department to receive the urgent care. Elobeid Teaching hospital is the oldest and biggest hospital in the Kordofan Region and is owned and operated by the North Kordofan state. Patients included in this study have been referred to the hospital from the states of Kordofan and Darfur. The hospital is comprised of an accident and emergency department, radiological department, Laboratory center with a blood bank, surgical specialty department, Medical specialty department as well as an operation complex with an intensive care department.

\section{Inclusion and exclusion criteria}

We include all patient presented to the hospital with Gunshot injuries, resulting from civilian altercations, during the study period and received treatment in the hospital. Any patients that were dead at time of presentation or died within the first 6 hours were excluded from the study population.

\section{Clinical assessment}


Primary assessment was done for all patients presented to the emergency department through the Advanced Trauma Life Support protocol. The emergency team checked each patient's airways, breaching, circulation and disability. Following the primary assessment, a primary investigation was done after the stabilization of the patients. Emergency procedure like chest tube insertions and surgical toilets and explorations of abdominal wounds, under local anaesthesia, were done in the emergency department. Lastly, the patients were categorized, according to their condition, to receive further treatment by the General Surgery or Orthopedic Units for any additional necessary surgeries or follow up.

\section{Operative treatments}

Operative surgeries such as laparotomy are urgently performed in cases of abdominal injury or internal bleeding. Orthopaedic operations are typically done within the 3-5 days. Optimization of patients was done preoperatively (to replace the blood loss) and reviewed review by anesthetist and request the relevant investigations. Following the optimization, patients will be followed by the responsible units, which will assess the patients in the outpatient clinic in intervals of 2 weeks, 1 month, 3 month, six months and 1 year depending on their condition.

\section{Data collection and analysis}

Flowchart sheets were used to collect the baseline characteristics of the patients. Age, sex, residence, education, occupation and causes of the quarrel were checked. Information regarding the site of bullet, condition at the time of presentation, diagnosis, complications and outcomes were determined. Types of operation and intervention done were determined based on each individual case. The data collected were entered and analyzed using SPSS version 21 statistical software (IBM Corporation, Chicago, IL). Results were tabulated and presented as frequencies and percentages, accordingly. For each test, $P<.05$ was considered statistically significant $(95 \% \mathrm{Cl})$.

\section{Results}

The total number of patients who were diagnosed with gunshot injuries and included in the study is 157 . The mean age of patients is 27.7 years old, ranging between 1 to 65 years old. The most common age group is 21-30 years. All patients' characteristics are shown in Table 1. Most of the patients in this study were males $87.9 \%$ and $46.2 \%$ of them are married. Twenty five percent of the patients were residents of Elobeid city while the rest were from outside the city. About two thirds of patients were either illiterate (36.1\%) or primary school level education $37.3 \%$ and their jobs are farmer or labeler in 36.1 and 28.5 percent respectively.

Table 2 demonstrates the anatomical site of gunshot wounds, diagnosis, and treatment done for the patients. The anatomical site of the wounds were found mainly in the lower limbs and upper limbs in 65 patients $(41.4 \%)$ and 36 patients $(22.9 \%)$ respective. Additionally, the least common wound site is perineum among with only $3(1.9 \%)$ patients being affected. The most common diagnosis among patients in this study were limb fractures and soft tissue injuries among $78(49.7 \%)$ and $45(28.7 \%)$ patients respectively. There were three patients diagnose with a head injury. Specific treatments in this 
study included wound debridement which was done for 91 (58.0\%) patients. Other treatments included bone fixation, laparotomy and chest tube insertion which were done for the rest of the patients.

More than 120 (75\%) of patients were cured and discharged in a good condition and $27(17.2 \%)$ patients were referred to specialized center for further treatment. Diagnosis of referred patients is shown in Fig. 1. Five (3.2\%) patients were discharge against medical advice and $5(3.2 \%)$ additional patients died. There is significant correlation ( $p$ value less than 0.05 ) between final management outcome and site of gunshot (Table 2). Hospital stay is was demonstrated in Table 3 and it was affected by diagnosis and treatment. A significant correlation ( $p$ value less than $<0.05$ ) was found between hospital stay and treatment. 
Table 1

Patient characteristics in the study $(\mathrm{N}=157)$

\begin{tabular}{|c|c|c|c|}
\hline Variables & & Frequency & Percentage \\
\hline \multirow[t]{5}{*}{ Age groups } & $<$ than 18 years & 28 & 17.8 \\
\hline & $18-29$ years & 65 & 41.4 \\
\hline & $30-39$ & 40 & 25.5 \\
\hline & $40-50$ & 15 & 9.6 \\
\hline & $>$ than 50 years & 9 & 5.7 \\
\hline \multirow[t]{2}{*}{ Gender } & Male & 138 & 87.9 \\
\hline & Female & 19 & 12.1 \\
\hline \multirow[t]{4}{*}{ Marital status } & Single & 54 & 34.2 \\
\hline & Married & 73 & 46.2 \\
\hline & Divorce & 6 & 3.8 \\
\hline & Widow & 3 & 1.9 \\
\hline \multirow[t]{2}{*}{ Residence } & In Elobeid & 40 & 25.3 \\
\hline & Out Elobeid & 118 & 74.7 \\
\hline \multirow[t]{5}{*}{ Level of education } & Illiterate & 57 & 36.1 \\
\hline & Primary School & 59 & 37.3 \\
\hline & Intermediate School & 24 & 15.2 \\
\hline & Secondary School & 11 & 7.0 \\
\hline & Under School Age & 7 & 4.4 \\
\hline \multirow[t]{6}{*}{ Occupation } & Labour & 45 & 28.5 \\
\hline & Farmer & 57 & 36.1 \\
\hline & Student & 14 & 8.9 \\
\hline & Housewife & 17 & 10.8 \\
\hline & Employer & 4 & 2.5 \\
\hline & Non employer & 21 & 13.3 \\
\hline
\end{tabular}


Table 2

Management out come in relation to site of Pullet, diagnosis and treatment

\begin{tabular}{|c|c|c|c|c|c|c|c|}
\hline \multirow[t]{2}{*}{ Variables } & & \multicolumn{4}{|c|}{ Management outcome } & \multirow[t]{2}{*}{ Total } & \multirow[t]{2}{*}{$P$ value } \\
\hline & & Cured & Referred & DAMA* & died & & \\
\hline \multirow{7}{*}{$\begin{array}{l}\text { Site OF } \\
\text { Pullet }\end{array}$} & Upper Limb & 33 & 0 & 3 & 0 & 36 & $.002^{\star \star}$ \\
\hline & Lower Limb & 55 & 9 & 1 & 0 & 65 & \\
\hline & Thorax & 10 & 4 & 1 & 0 & 15 & \\
\hline & Abdomen & 12 & 7 & 0 & 5 & 24 & \\
\hline & Back and Spine & 4 & 2 & 0 & 0 & 6 & \\
\hline & Head and Neck & 4 & 4 & 0 & 0 & 8 & \\
\hline & Perineum & 2 & 1 & 0 & 0 & 3 & \\
\hline \multirow[t]{6}{*}{ Diagnosis } & limb fracture & 66 & 8 & 4 & 0 & 78 & .991 \\
\hline & visceral perforation & 8 & 4 & 0 & 4 & 16 & \\
\hline & rib fracture & 8 & 2 & 0 & 1 & 11 & \\
\hline & Head injury & 1 & 2 & 0 & 0 & 3 & \\
\hline & soft tissue injury & 35 & 9 & 1 & 0 & 45 & \\
\hline & Internal bleeding & 2 & 2 & 0 & 0 & 4 & \\
\hline \multirow[t]{6}{*}{ Treatment } & wound debridement & 70 & 14 & 5 & 2 & 91 & .823 \\
\hline & internal fixation & 6 & 1 & 0 & 0 & 7 & \\
\hline & eternal fixation & 16 & 0 & 0 & 0 & 16 & \\
\hline & laparotomy & 9 & 6 & 0 & 3 & 18 & \\
\hline & chest tube insertion & 7 & 4 & 0 & 0 & 11 & \\
\hline & Internal \& external fixation & 12 & 2 & 0 & 0 & 14 & \\
\hline Total & & 120 & 27 & 5 & 5 & 157 & \\
\hline
\end{tabular}


Table 3

Hospital stay related to diagnosis and treatment

\begin{tabular}{|c|c|c|c|c|c|c|c|c|}
\hline & & \multicolumn{7}{|c|}{ Hospital stay } \\
\hline & & $\begin{array}{l}0-5 \\
\text { days }\end{array}$ & $\begin{array}{l}6-10 \\
\text { days }\end{array}$ & $\begin{array}{l}11-15 \\
\text { days }\end{array}$ & $\begin{array}{l}16-20 \\
\text { days }\end{array}$ & $\begin{array}{l}>20 \\
\text { days }\end{array}$ & TOTAL & $\begin{array}{l}\mathrm{P} \\
\text { value }\end{array}$ \\
\hline \multirow[t]{6}{*}{ Diagnosis } & limb fracture & 11 & 13 & 8 & 8 & 38 & 78 & \multirow[t]{6}{*}{.465} \\
\hline & $\begin{array}{l}\text { visceral } \\
\text { perforation }\end{array}$ & 3 & 3 & 2 & 3 & 5 & 16 & \\
\hline & rib fracture & 0 & 1 & 2 & 0 & 8 & 11 & \\
\hline & Head injury & 3 & 0 & 0 & 0 & 0 & 3 & \\
\hline & soft tissue injury & 10 & 12 & 4 & 0 & 19 & 45 & \\
\hline & Internal bleeding & 1 & 0 & 0 & 1 & 2 & 4 & \\
\hline \multirow[t]{6}{*}{ Treatment } & $\begin{array}{l}\text { wound } \\
\text { debridement }\end{array}$ & 19 & 21 & 9 & 7 & 35 & 91 & \multirow[t]{6}{*}{0.00} \\
\hline & internal fixation & 1 & 1 & 3 & 0 & 2 & 7 & \\
\hline & eternal fixation & 0 & 2 & 2 & 0 & 12 & 16 & \\
\hline & laparotomy & 4 & 2 & 1 & 4 & 7 & 18 & \\
\hline & $\begin{array}{l}\text { chest tube } \\
\text { insertion }\end{array}$ & 2 & 1 & 1 & 0 & 7 & 11 & \\
\hline & $\begin{array}{l}\text { Internal \& external } \\
\text { fixation }\end{array}$ & 2 & 2 & 0 & 1 & 9 & 14 & \\
\hline
\end{tabular}

\section{Discussion}

Gunshot injuries represent a major health problem health worldwide with direct burdens to health service and economy [9]. Sudan is considered one of the sub-Saharan countries affected by internal conflict, thus, consequently gunshot-related injuries and mortalities are common [10]. Conflicts tend to arise due to different tribes and ethnic groups competing for basic resources in one place. Poverty, increased intolerance in the community and armed robberies are all considered to be important factors leading to increased gunshot violence in different parts of the country [5]. To the best of our knowledge there were no studies that determine the extent of firearm injuries in Sudan. In this study, we reviewed the data (clinical presentation, treatments and management outcome) of 157 patients presented to the hospital with gunshot wounds due to various causes in the period of January 2014 to January 2019 to assess the pattern, causes, management and the outcome. The total number of patients reviewed in this study is 
same or slightly higher than some an available national and international $[6,11,12]$ data but still less than reported number from USA and South Africa $[8,13,14]$.

Gunshot injuries affects all age groups at different stages of life, but are more prevalent in younger age groups [14] The most common age group affected by gunshot injury in this study is the younger age which is in line with what has been previously reported by other studies $[5,14,15]$. However, $18 \%$ of the study's participant is comprised of the pediatrics age group. This outcome is unusual and is considered to be high compared to a study done in Nigeria [15]. Interestingly, our numbers, with regards to gunshot injuries in pediatric patients, are similar to a report from South Africa [13]. Like other previous studies [5, $9,12,14,16,17]$, our data revealed that males were disproportionately affected, and this could explained by their outdoors presence most of the time because of societal gender roles.

The most common anatomical site of the body affected by nonfatal firearm injuries are the upper or lower limbs extremities including soft tissue as well as bone tissue [6]. In this study the lower limb followed by the upper limb are the most common sites injured (65\%). Conversely, the perineum was found to be the least affected site (2\%). These findings are like those reported in previous literature $[6,8,13]$. However, results from a study done in Sudan, during the period of civil demonstrations, showed only one patient with a gunshot wound in the lower extremity hip bone [18]. The extent of injury and tissue damage following gunshots depends on several factors such as wound ballistics, tissue structure and the respective anatomical relationships [19]. Our data showed limbs fracture with local soft tissue injuries as the most common presenting diagnosis, followed by visceral perforations, rib fractures and head injuries. These findings are similar to studies conducted previously $[8,13,14]$.

Furthermore, a study done by Livingstone et al in a major trauma center USA showed that $75 \%$ of patients admitted with gunshot wounds underwent at least one surgical intervention procedure [20]. Almost all our study's patients underwent one or more surgical intervention(s) ranging from minor wound debridement to exploratory laparotomy. Other surgical procedures included bone internal, external fixation or both, and chest tube insertion. However some other report showed only $53 \%$ of the patients required a surgical intervention [6]. The economic aspect of prolonged hospital stays and their burden on the health care system was addressed. About half of the patients in our study stayed in the hospital for more than 20 days. This is considered to be a significantly long hospitalization period in comparison to other studies $[17,21]$. However, this long stay can be explained by the presence of open limb fractures which usually need external fixation and frequent wound debridement and dressing. The overall outcome of the patient in our data was good, where $75 \%$ of patients were cured and discharged in a good condition. About $17 \%$ of patients were referred to specialized center for further management that are not a available at our medical center.

Firearm injuries have the highest case fatality rate in every age group, with a mortality rate of $15.3 \%$ for gunshot wounds in according to a report from the American College of Surgeons (ACS) National Trauma Data Bank [6]. Another study done in the Scandinavian Trauma Center revealed mortality rate of $12.8 \%$ for firearm injuries. Study done by Mansor et al showed mortality rates of $7.7 \%$ in civilian gunshot injuries 
and $10 \%$ for stray bullets [17]. In our data the mortality rate was $3.1 \%$, which is comparable data reported from the London Major Trauma Center. [12]. The deaths in our study population occurred within the first and second weeks of injury. All 5 deceased patients had gunshots to the abdomen, which are known carry high morbidity and mortality rate according to a national and international studies [5, 22, 23]. Laparotomy was done for those patients with findings of internal organs injuries. One patient underwent chest tube insertion in addition to laparotomy due associated chest injury. However study done in Nigeria showed no mortality rate.[15].

\section{Conclusion}

Most of the patient in this study were young males. Upper and lower limb fractures are the most common presentations. Wound debridement, bone fixation and laparotomy are the most common treatments with significant success rates, despite prolonged hospital stay.

\section{Declarations}

\section{Authors' contributions}

MYB, MBAK and AAK are the treating doctors of patients. MYB and MDAG conceived the idea and designed the study. MDAG and MYB did the data collection and analysis. MDAG and MYB wrote the manuscript and made final approval. All authors read and approved the final manuscript

\section{Funding author}

Authors declare no fund

\section{Availability of data and materials}

Available upon request

\section{Ethics approval and consent to participate}

Approval of the study protocol was obtained by the Ohio State Behavioral and Social Science Institutional Review Board (IRB) prior to study initiation. As this was a quality improvement initiative for all sites, no consent was required from parents.

\section{Consent for publication}

The consent for publication was obtained from each study participants during data collection.

\section{Competing interests}

The authors of this study have no financial relationships or conflicts of interest relevant to this article to disclose. 
Acknowledgements

The authors would like to thank the patients' record Staff. Additionally, we thank Ahmed Bagit for grammar reviewing.

\section{References}

1. Hussain AM, Lafta RK. Accidents in Iraq during the period of conflict (2003-2016). Qatar Med J. 2019;2019(3):14.

2. El Tayeb S, et al. Socioeconomic and disability consequences of injuries in the Sudan: a communitybased survey in Khartoum State. Inj Prev. 2015;21(e1):e56-62.

3. El Tayeb S, et al. Injuries in Khartoum state, the Sudan: a household survey of incidence and risk factors. Int J Inj Contr Saf Promot. 2014;21(2):144-53.

4. Hugenberg F, et al. Firearm injuries in Nairobi, Kenya: who pays the price? J Public Health Policy. 2007;28(4):410-9.

5. Elhajl.Tibin AMA, Mohamed EAhmed. Pattern and Outcome of abdominal gunshot wounds in ElFashir Teaching Hospita. Khartoum Medical Journal 2016. 09(03): p. 1291-1296.

6. Backman PB, et al. Epidemiology of firearm injuries in a Scandinavian trauma center. Eur J Trauma Emerg Surg. 2020;46(3):641-7.

7. Martin C, et al. The burden of gunshot injuries on orthopaedic healthcare resources in South Africa. S Afr Med J. 2017;107(7):626-30.

8. Aspelund $\mathrm{AL}$, et al. Evaluating trauma scoring systems for patients presenting with gunshot injuries to a district-level urban public hospital in Cape Town, South Africa. Afr J Emerg Med. 2019;9(4):1936.

9. Kaim Khani GM, et al. Pattern of bony injuries among civilian gunshot victims at tertiary care hospital in Karachi, Pakistan. Chin J Traumatol. 2015;18(3):161-3.

10. Fares J, et al., Conflict Medicine in the Arab World. 2020: p. 1-16.

11. Zgheib H, et al. Gunshot Injuries in Lebanon: Does Intent Affect Characteristics, Injury Patterns, and Outcomes in Victims? J Emerg Trauma Shock. 2019;12(2):117-22.

12. Norton J, et al. Shooting up? Analysis of 182 gunshot injuries presenting to a London major trauma centre over a seven-year period. Ann R Coll Surg Engl. 2018;100(6):464-74.

13. Engelmann EWM, et al., Epidemiology and injury severity of 294 extremity gunshot wounds in ten months: a report from the Cape Town trauma registry. SA Orthopaedic Journal, 2019. 18(2).

14. Fowler KA, et al. Firearm injuries in the United States. Prev Med. 2015;79:5-14.

15. M, O. and Sp A. Civilian Gunshot Injuries: Experience from Sokoto, North-West, Nigeria. Journal of Trauma \& Treatment, 2016. 05(01).

16. Muhammad Nazir khan SAS, Zakaullah Malik A, Ahmed MA, Asim. PATTERN OF FACIAL GUNSHOT AND BLAST INJURIES AMONGST LAW ENFORCING FORCES. Pak Armed Forces Med J 2016. 66(4)): 
p. 515-19.

17. Salah Mansor ZB. The Impact of the Method of Gunshot Injury: War Injuries vs.. Stray Bullets vs. Civilian Fighting. Journal of the College of Physicians and Surgeons Pakistan 2015. Vol. 25(4)): p. 281-285.

18. Dahab $\mathrm{M}$, et al. Deaths, injuries and detentions during civil demonstrations in Sudan: a secondary data analysis. Confl Health. 2019;13:16.

19. Stefanopoulos PK, et al. Wound ballistics 101: the mechanisms of soft tissue wounding by bullets. Eur J Trauma Emerg Surg. 2017;43(5):579-86.

20. Livingston DH, et al., Unrelenting violence: an analysis of 6,322 gunshot wound patients at a Level I trauma center. J Trauma Acute Care Surg, 2014. 76(1): p. 2-9; discussion 9-11.

21. Kong VY, et al. Discrepancy in clinical outcomes of patients with gunshot wounds in car hijacking: a South African experience. S Afr J Surg. 2019;57(4):25-8.

22. Al Rawahi AN, et al. Outcomes of selective nonoperative management of civilian abdominal gunshot wounds: a systematic review and meta-analysis. World J Emerg Surg. 2018;13:55.

23. Philipp Lichte RO, Binnebösel M, Wildenauer R, Pape H-C, Kobbe P. A civilian perspective on ballistic trauma and gunshot injuries. Scandinavian Journal of Trauma Resuscitation Emergency Medicine. 2010;18(35):2-8.

\section{Figures}

\section{Patients who are cured or referred related to diagnosis}

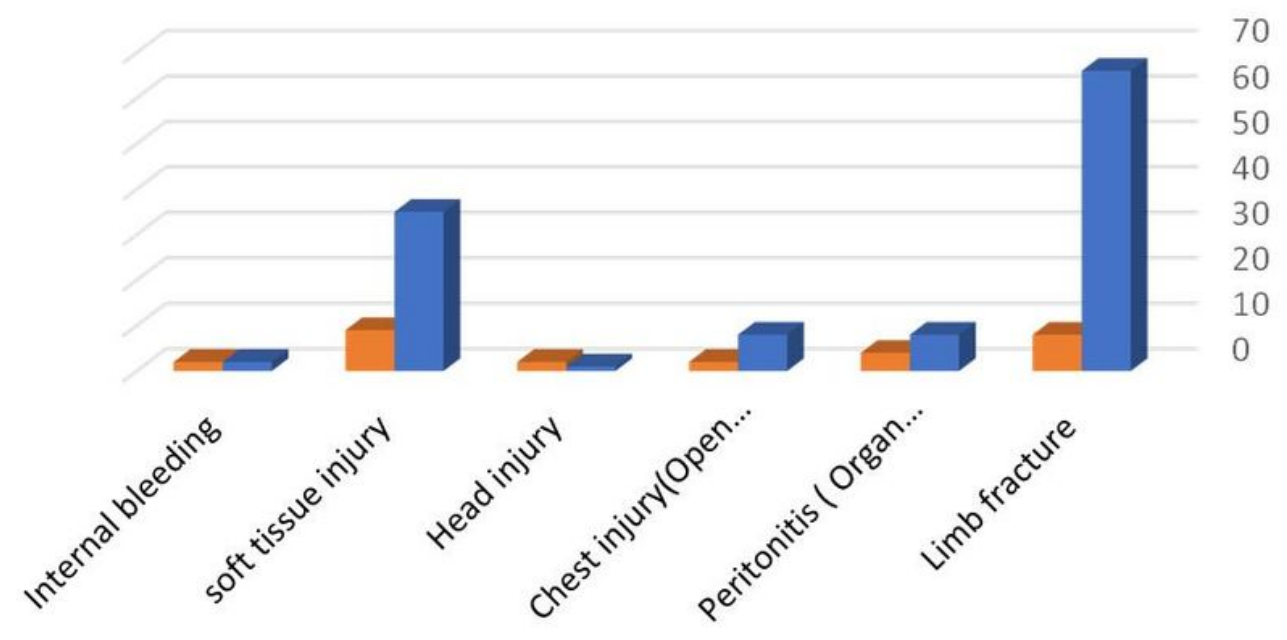

Cured (Discharge in good condition)

- Referred to higher care

\section{Figure 1}

Patients who are cured or referred related to diagnosis 